\title{
NOWA PLANETA: KU NADZOROWANEJ WOLNOŚCI. DYSKURSY I TRENDY
}

\begin{abstract}
Kazimierz Krzysztofek, Nowa PlaNETa: ku nadzorowanej wolności. Dyskursy i trendy [The New PlaNET: Towards Surveilled Freedom], edited by M. Baranowski, „Człowiek i Społeczeństwo”, vol. XL, Poznań 2015, pp. 29-46, Adam Mickiewicz University Press. ISBN 978-83-232-2964-3, ISSN 0239-3271.
\end{abstract}

The article is aimed at analyzing two trends, which at the same time constitute two discourses. The Author is focusing on their analysis avoiding to state to what extent they are contradictory or complementary, or in what degree they place themselves in different value orders, thus hardly subjected to be analyzed on a comparable scale. The first trend describes the dispersed, personalized and hyper-individualistic society whilst the second one is about a society heading for bureaucratization, quantification, monitoring and surveillance. Both trends are reflecting real processes of conflict and exchange. On the one hand they are gearing each other, and on the other hand they are in opposing relationships.

Kazimierz Krzysztofek, SWPS Uniwersytet Humanistycznospołeczny, Instytut Nauk Społecznych, ul. Chodakowska 19/31, 03-815 Warszawa, Poland, e-mail: kkrzysz1@swps.edu.pl

\section{Wstęp: hipotezy badawcze}

Wiedza o nowych formach społecznych wciąż jest budowana raczej przez społeczne imaginaria - by użyć określenia Charlesa Taylora - niż empirię, której nadal jest relatywnie mało, mamy bowiem do czynienia z przyspieszoną historią w trakcie jej dziania się. Z tego powodu ciągle niewiele jest zweryfikowanych teorii socjologicznych i społecznych, a dużo sprzecznych dyskursów. W tej sytuacji opis każdego zjawiska, jeśli ma być w miarę wyczerpujący, musi lokować się w ramach różnych dyskursów. Monodys- 
kursywnie można mówić o faktach i ustaleniach, które nie budzą sporów i sprzecznych ocen. Tam zaś, gdzie wchodzi w grę ewaluacja, oceniać dane zjawisko społeczne można tylko transdyskursywnie. Jeśli chodzi o społeczeństwo Sieci, to wiedza o nim jest raczej zbiorem dyskursów niż jednolitą teorią socjologiczną, która mogłaby zyskać szerszą aprobatę.

Nie ma w tym nic dziwnego, ponieważ Internet w obecnej postaci liczy sobie nie więcej niż dwie dekady, a punkt krytyczny - jako przestrzeń społeczna, do której przenosi się coraz więcej aktywności - przekroczył dopiero przed dekadą. Stąd tyle sprzecznych perspektyw czy zmian stanowisk pod wpływem nowych trendów. Bierze się to często z przypisywania części jakiegoś fenomenu cech całości. Można więc odnieść wrażenie, że jesteśmy na bakier z Arystotelesowską logiką dwuwartościową. Dwa sprzeczne sądy nie mogą być jednocześnie prawdziwe, co za Mikołajem z Kuzy można określić mianem coincidentia oppositorum.

W przypadku Internetu mamy do czynienia z dwoma sprzecznymi stanowiskami w kwestii wolności i zniewolenia. Piśmiennictwo krajowe i zagraniczne traktujące o fenomenie Internetu, zwłaszcza uspołecznionego w wersji Web 2.0, koncentruje się na przedstawieniu rozbieżnych ocen: od kwalifikowania go jako dobrodziejstwa i wyzwolenia, po dyskredytowanie jako „złodziejstwa” i zniewolenia. W jednych ujęciach Internet to zbiorowa mądrość sieciowego ludu, w innych - kolektywna ignorancja. Jednoznaczne kwalifikowanie aksjologiczne tego fenomenu jest ryzykowne, gdyż to, co dla jednych jest dobre i korzystne, dla innych niekoniecznie. Poprzestanie na ocenach etycznych byłoby dość jałowe, dlatego warto spojrzeć na Internet bez namiętności, „poza monitor” emocji, z kilku perspektyw badawczych.

\section{Web 2.0 jako dobrodziejstwo i wolność}

Trafna wydaje się metafora, że Internet to fala czołowa wielkiej zmiany społeczne tworzenie nowej rzeczywistości. Cała plejada badaczy z różnych dziedzin poświęca temu zjawisku wiele uwagi i sympatii, by wymienić prace o kolektywnej inteligencji (Pierre Levy, Derrick de Kerckhove ${ }^{1}$ ), „inteligencji roju ludzkiego” (Howard Rheingold²), zbiorowej mądrości

${ }^{1}$ P. Levy, Collective Intelligence. Mankind's Emerging World in Cyberspace, Reading, Mass. 1997; D. de Kerckhove, Inteligencja otwarta. Narodziny społeczeństwa sieciowego, tłum. A. Hildebrandt, Warszawa 2001.

${ }^{2}$ H. Rheingold, Smart Mobs. The Next Social Revolution. Transforming Cultures and Communities in the Age of Instant Access, Cambridge, Mass. 2002. 
(James Surowiecki ${ }^{3}$ ), „katedry i bazaru” (Eric S. Raymond ${ }^{4}$ ), Multitude - rzeszy samoorganizujących się podmiotów (Antonio Negri, Michael Hardt ${ }^{5}$ ), wikinomii (Don Tapscott, Anthony D. Williams ${ }^{6}$ ), wolnej kultury (Lawrence Lessig7), produkcji niszowej („długi ogon” - more of less, Chris Anderson $^{8}$ ), kultury konwergencji (Henry Jenkins ${ }^{9}$ ) czy bogactwa sieci (Yochai Benkler ${ }^{10}$ ).

Dzisiejszy Internet jest czymś pośrednim między komunikacją masową i interpersonalną. Zachwycano się nim, bo miał posmak nowości. Dzięki niemu i wolnemu oprogramowaniu powstają technologie kooperacji dla zwykłych użytkowników, a tym samym samoorganizujące się sieci, wspólnoty computingu gridowego, platformy zasobów (i dzielenie się nimi w systemie peer to peer), grupy sieciotwórcze integrujące infrastrukturę komunikacyjną z relacjami społecznymi, społeczny software, społeczności zaufania, społeczności kreujące wiedzę (wikipedia), blogosfera i inne ${ }^{11}$. Wraz z tymi technologiami rodziła się wiara w możliwość odzyskania władzy nad symbolami konstytuującymi tożsamość, samodefiniowania się i samopotretowania przez upublicznianie dyskursów mniejszościowych; słowem - wiara w demokrację semiotyczną.

Dzięki indeksowaniu przez rzesze użytkowników odkrywamy pokłady informacji i wiedzy, do których w inny sposób nie moglibyśmy dotrzeć. Tak zyskujemy dostęp do rzadkich zasobów. Jeśli nie byłoby wymiany plików w systemie peer to peer, to - przy wszystkich zastrzeżeniach natury prawnej - np. kinomani zdani byliby tylko na ofertę dystrybutorów, dla których liczy się głównie oglądalność i zyski. Użytkownicy sami wprowadzają do

3 J. Surowiecki, The Wisdom of Crowds: Why the Many Are Smarter Than the Few and How Collective Wisdom Shapes Business, Economies, Societies and Nations, New York 2005.

${ }^{4}$ E.S. Raymond, The Catheral and the Baazar. Musing on Linux and Open Source by an Accidental Revolutionary, New York 2001.

${ }^{5}$ M. Hardt, A. Negri, Multitude. The War and Democracy in the Age of Empire, New York 2004.

${ }^{6}$ D. Tapscott, A.D. Williams, Wikinomics, How Mass Collaboration changes Everything, Richmond 2006.

${ }^{7}$ L. Lessig, Wolna kultura, Warszawa 2005.

${ }^{8}$ Ch. Anderson, The Long Tail, New York 2006.

${ }^{9}$ H. Jenkins, Kultura konwergencji, tłum. M. Bernatowicz, M. Filipiak, Warszawa 2006.

${ }^{10}$ Y. Benkler, The Wealth of Networks: How Social Production Transforms Markets and Freedom, Yale 2006.

${ }^{11}$ H. Rheingold, A. Savery, K. Vian, Technologies of Cooperation, Palo Alto 2005. 
obiegu utwory niekoniecznie atrakcyjne rynkowo, ale dla nich wartościowe, nadając im nowe znaczenia. Tim O’Reilly nazywa Internet drugiej generacji (Web 2.0) architekturą uczestnictwa. To kolejna próba uspołecznienia Sieci po udostępnieniu wolnego oprogramowania w środowisku GNU/ Linuxa. Jest to batalia o to, czy Internet będzie projektem tylko konstruktywistycznym (corporate driven), czy także adaptacyjnym środowiskiem użytkownika (user centered), w którym będzie on mógł realizować swoje potrzeby.

W dzisiejszym Internecie toczy się walka między spontanicznością a organizacją i instytucjonalizacją, co nie jest niczym nowym, gdyż zawsze rozwijały się ruchy społeczne i zawsze były podejmowane próby ich okiełznania. Jest to konflikt między taksonomią, czyli ustalonym przez ekspertów systemem indeksowania i klasyfikowania treści, a tym, co określa się mianem folksonomy. Są to dwie kultury uczestnictwa w Internecie. Na zaufaniu do mądrości internautów zbili majątek twórcy Google, którzy opracowali algorytm swojej przeglądarki na podstawie częstości odsyłania do konkretnych stron, czyli hierarchizowania dokumentów przez internautów.

Oznacza to, że każdy użytkownik ma potencjalnie władzę definiowania ludzi, rzeczy, zjawisk wydarzeń wedle własnych pojęć i znaczeń. Daje to szanse na demokrację, budowanie podmiotowości, eksperymentowanie z tożsamością. Możliwość czerpania z bezmiaru symboli i produkcji własnych czyni podmiot ludzki wysoko semiotycznym. A taki podmiot jest potrzebny. Konsumpcja znaków jest jednocześnie ich kreowaniem i puszczaniem w obieg; każde odczytanie znaków jest mnożeniem następnych.

Można więc powiedzieć, że użytkownicy budują kolektywną wartość poprzez realizację własnych zainteresowań i korzyści. Ich zainteresowania zyskują w ten sposób wymiar społeczny i przyczyniają się do poszerzania wspólnie eksploatowanych zasobów ${ }^{12}$.

Przed kilkunastu laty, gdy Internet w dzisiejszym kształcie (w wersji 2.0) dopiero się rozwijał, był hierarchiczny i zinstytucjonalizowany (monopol Netscape’a i oligopol kilku silników wyszukujących - search engines): Infoseek, Excite!, Yahoo, AltaVista, Lycos i inne, fora dyskusyjne były nieliczne, a blogi jeszcze nie istniały. Stanowił on więc przede wszystkim medium komunikacji, a nie środowisko społeczne. Dominowali ci, którzy mieli władzę nadawania znaczeń i kierowali nas w odpowiednią stronę. Takie jest prawo wielości ${ }^{13}$. Użytkownicy pragną mieć władzę semiotycz-

12 J. Hofmokl, Internet jako dobro wspólne, Warszawa 2008.

${ }^{13}$ Nawiązuję tu do konceptu multitude Michaela Hardta i Antonia Negriego. Por. M. Hardt, A. Negri, Multitude... 
ną, która sama w sobie jest bogactwem. Nie są więc skazani na pojemność informacyjno-poznawczą najbliższego otoczenia, mają bowiem dostęp do ogromnych zasobów.

Dobrodziejstwa to wszystko to w Internecie, co daje ludziom możliwość wyrażania siebie, ułatwia kooperację z innymi, budowanie wspólnot, bycie użytecznym i twórczym, daje satysfakcję z wnoszenia wkładu w jakieś dzieło, odnajdywania czy konstruowania tożsamości, sensu, znaczeń, samorealizację i pozyskiwanie nowych zasobów, wiedzy i kompetencji, poczucie podmiotowości, dawanie wsparcia. Pisanie nawet niezbyt mądrego bloga bywa często bardziej twórcze niż praktyki couch potato (przesiadywanie przed telewizorem po kilkanaście godzin na dobę).

Serwisy społecznościowe to efekt kuli śnieżnej: każdy dokłada coś do wspólnej puli. To tak jakby oddać pióra, kamery i mikrofony w ręce ludu: widzów, słuchaczy. To podważa pozycję gatekeeperów, którzy wcześniej niepodzielnie decydowali o tym, jaka zawartość znajdzie się w kanałach informacyjnych.

Podsumowując oczywiste pozytywy: samoportretowanie się, zyskiwanie władzy nad symbolami, empowerment, każdy nosi buławę w tornistrze, może być netokratą, „rewolucjonistą w Sieci”, zdobywcą - poczuć się Markiem Polo cyberprzestrzeni. Taka demokracja sieciowa upodmiotawia. Internet jest dla wielu osób spełnieniem marzenia o równych szansach, realizacją jednego z trzeciej generacji praw człowieka (praw kulturowych uzupełniających prawa polityczne i socjalne) - prawa do komunikowania się. Realizacja tego prawa poprawia efektywność działań społecznych, które mniej zależą od zewnętrznej regulacji życia, a bardziej od autonomii jednostek. Web 2.0 jawi się więc jako kontrola mainstreamu - dominujących dotychczas instytucji. Można to porównać do wpuszczenia szczupaka do stawu z tłustymi karpiami.

\section{Internet jako „złodziejstwo" i zniewolenie}

Jednym z coraz liczniejszych głosów opozycyjnych wobec optymistycznego nurtu refleksji o społecznej produkcji treści w sieciach jest książka Andrew Keena Kult amatora. W podtytule książki autor umieścił intrygujące i prowokujące stwierdzenie, że Internet zabija kulturę ${ }^{14}$. Wszakże Keena interesuje nie tyle Internet, ile jego najnowsze wcielenie - Web 2.0. Dlaczego zabija?

${ }^{14}$ A. Keen, Kult amatora. Jak Internet zabija kulturę, tłum. M. Bernatowicz, K. Topolska-Ghariani, Warszawa 2007. 
Dlatego że jest tworzony przez amatorów w najbardziej negatywnym znaczeniu tego słowa - po prostu ignorantów i nieuków.

Można mieć pretensje do autora, że „mordercą” uczynił cały Internet, a tak naprawdę na kartach książki przedstawia zarzuty wobec Web 2.0. Popełnia zatem grzech pars pro toto. W analizie naukowej by to nie uszło, ale autor nie zamierzał pisać chłodnej analizy sine ira et studio. Chodziło mu o danie czytelnikowi dobrze udokumentowanego dyskursu krytycznego. Już samo krytyczne zaangażowanie autora zachęca do dyskusji z jego poglądami.

Andrew Keen nie jest jedynym zaprzysięgłym wrogiem Internetu w jego obecnej postaci. Prawie 10 lat przed nim, a 10 lat w historii tego medium to cała epoka, słynny łowca komputerowych szpiegów, Clifford Stoll, widział w Internecie nie sezam, a wielkie śmietnisko, wysypisko danych, z którego trudno wyłowić coś wartościowego ${ }^{15}$. Internet miał też wielu krytyków we Francji, m.in. Philippe’a Bretona ${ }^{16}$, choć trochę na innym tle (Internet zabił ich „dziecko”, z którego byli dumni - Minitel). Wiele krytycznych akcentów znaleźć można w książce Johna Batelle’a o imperializmie Google’a ${ }^{17}$.

Keen jest jednak pionierem w krytyce Web 2.0. I tym przede wszystkim zwróciła na siebie uwagę jego książka. Krytykuje w niej nie tylko Web 2.0, ale także jego obrońców, a wśród nich Lawrence’a Lessiga. Keen ustawia się w opozycji, kwestionuje w Web 2.0 niemal wszystko, przestawia znaki aksjologiczne. To, co dla jego orędowników jest wrogiem - cały mainstream komercyjnych mediów, przemysłów kultury i wiedzy, dla Keena jest ostoją kultury, bastionem cywilizacji, infrastrukturą pewnych i bezpiecznych instytucji, które stanowią gwarancję, że w Sieci nie będzie oszustwa.

Keen nie przyznaje tego wprost, ale można odnieść wrażenie, że jawi mu się to, co Garret Hardin blisko pół wieku temu nazwał tragedią wspólnego pastwiska - prymitywnego commons, gdzie się „wyżera do gruntu trawę na długość łańcucha”, po czym zostawia ją wyjałowioną. Jego zdaniem „grodzenie kultury i wiedzy” sprawdziło się i trzeba przy nim pozostać.

Książka Keena maluje obraz spodlonego świata nowego Internetu, w którym każdego można oczernić, szantażować, wejść z butami w jego życie, w którym jest wszystko, co najgorsze: podła konkurencja, epidemia donosicielstwa, bezkarności, próżności, ekshibicjonizmu, webwandalizmu, słowem: pandemonium. Tak ostra krytyka to ukryta tęsknota za przemijającym światem, jaki znamy, oraz lęk przed niszczącym żywiołem.

${ }^{15}$ C. Stoll, Krzemowe remedium, Poznań 1996.

${ }_{16}$ Ph. Breton, Le culte de l'internet: une menace pour le lien social?, Paris 2000.

17 J. Battelle, Szukaj. Jak Google i konkurencja wywołali biznesowq i kulturowq rewolucję, Warszawa 2006. 
Podsumowując argumenty wyrażane przez zwolenników i krytyków, można pokusić się o pewną refleksję. Apologia i krytyka Internetu jest coraz częściej zniuansowana. Zwraca się uwagę, że kategorie wolności i zniewolenia powinno odnosić się raczej do konkretnych przypadków niż do ogółu użytkowników. Internet daje wolność tym, którzy czują się wolni, mają własny system aksjologiczny wartościowania treści i niemałe zasoby intelektualne, aby odróżnić to, co wartościowe, od tego, co jest pozbawione wartości, ich umiejscowienie kontroli jest wewnątrz, mają poczucie kontroli nad środowiskiem cyfrowym, w którym się „zanurzają”. Jeśli zaś tych walorów nie mają, to są podatni na zniewolenie, wolność staje się dla nich wolnością szkodzenia sobie, „wolnością we własnym odmóżdżaniu”, by posłużyć się określeniem Nicholasa Carra ${ }^{18}$. Kiedy Carr wskazuje na trend, którym jego zdaniem jest ogłupianie użytkowników przez Internet, w tym samoogłupianie się, to takie stwierdzenie ma niewielką wartość poznawczą, bo nie wiemy, nie mając danych, ilu ludzi ogłupia, a ilu wzbogaca. To zależy od wielu czynników, m.in. od zasobów intelektualnych, jakimi dany użytkownik dysponuje, zdolności krytycyzmu, wiedzy, wartościowania rzeczy i zjawisk. Powszechnie znana jest mądrość, że podróże kształcą, ale przede wszystkim wykształconych, którzy są w stanie najwięcej na tych podróżach skorzystać. To samo dotyczy Internetu - bywa on śmietnikiem, wysypiskiem danych, ale także skarbnicą wiedzy, sezamem, by jako przykład wymienić portal TED oferujący inspirujące wykłady prowadzone przez wybitnych fachowców, Khan Academy - dziesiątki tysięcy lekcji ze wszystkich dziedzin, czy otwarte platformy edukacyjne (OpenCourseWare) udostępniane wszystkim zainteresowanym przez znane uniwersytety, z Harvardem i MIT na czele ${ }^{19}$.

Generalnie ci, którzy wskazywali na plusy i minusy technologii cyfrowych, mniej odnosili się do wolności czy zniewolenia, a bardziej do rozwoju inteligencji, ulepszania człowieka (transhumanizm) albo w drugą stronę - do niszczenia więzi, kradzieży, anarchii, chorego indywidualizmu, narcyzmu, „cyfrowego maoizmu”20 czy terroru klikalności ${ }^{21}$. Obecnie z trudem można

${ }^{18}$ N. Carr, The Shallows. What the Internet is Doing to Our Brains, New York 2010.

${ }^{19}$ K. Krzysztofek, Open Knowledge Society in the Epoch of Networks, w: B. Poskrobko (red.), Sustainable Development versus Knowledge-Based Society, Białystok 2009, ss. 131-148.

${ }^{20}$ J. Lanier, Digital Maoism: The Hazards of the New Online Collectivism, http:// www.sampletheweb.com/2006/06/09/digital-maoism-the-hazards-of-the-new-onlinecollectivism-by-jaron-lanier/ [12.08.2014].

${ }^{21}$ E. Morozov, To Save Everything, Click Here: The Folly of Technological Solutionism, New York 2013. 
znaleźć autorów, którzy apologetyzują technologie cyfrowe. Jednym z nich jest Clive Thompson, który w książce Smarter Than You Think. How Technology Is Changing Our Minds For the Better ${ }^{22}$ przepowiada nadzwyczajny rozwój intelektu ludzkiego.

W jaki sposób wyjaśnić tę falę pesymizmu? Może do tego posłużyć model krzywej - w pierwszej fazie ujawnia się przewaga pozytywnych cech nowych technologii. Im bliżej wierzchołka krzywej, tym bardziej dochodzą do głosu zjawiska niekorzystne, ale jest jeszcze chwiejna równowaga. W miarę upowszechniania się technologii (tj. opadania krzywej) zaczynają przeważać zjawiska negatywne.

Dyskurs zniewolenia nasilił się głównie w efekcie pojawienia się Big Data, przy czym chodziło przede wszystkim o ochronę prywatności w Sieci, a także o anonimowość aktorów, która, jak się słusznie sądzi, podważa istotę społeczeństwa, nie można bowiem sobie wyobrazić społeczeństwa anonimowego.

To doprowadziło wybitnego znawcę problematyki Internetu, Jonathana Zittraina, autora książki The Future Internet and How to Stop It ${ }^{23}$, do następujących wniosków. Z jednej strony mamy w Internecie chaos, z drugiej jest to rekompensowane twórczością i innowacjami, rodzi przełomowe technologie (disruptive technologies) dzięki uczestnictwu zwirtualizowanych mas - milionów kreatywnych netterów, choć to nadal mniejszość użytkowników Sieci. Wynika z tego obfitość krzyżujących się inspiracji. Użytkownicy inspirują się nawzajem swymi ideami i pomysłami. Kreatywność wzrasta, a tempo innowacji ulega przyspieszeniu.

Po drugiej stronie znajduje się pokusa, by Internet ograniczyć. Choć wynikają z tego straty z powodu zredukowanej twórczości, to zyski z tytułu większego bezpieczeństwa okażą się większe - Internet stanie się bardziej zamknięty, „sterylny”, stabilny, przewidywalny, mniej twórczy, słowem: niegeneratywny. Ulubione przez Zittraina słowo tethered („na uwięzi”) opisuje tę cechę przyszłego Internetu, który będzie rutynowy dzięki samej technologii, a ta sprawi, że wszelkie urządzenia sieciowe, z komputerem i smartfonem na czele (różnica między nimi jest coraz mniejsza), będą coraz bardziej bezpieczne (user friendly). Oba te urządzenia mają zamknięte oprogramowanie, co ma ograniczać swobodę hakerów i innych tego typu osób w eksperymentowaniu z tymi urządzeniami, łamaniu kodów źródłowych.

${ }^{22}$ C. Thompson, Smarter Than You Think. How Technology Is Changing Our Minds For the Better, New York 2012.

${ }^{23}$ J.L. Zittrain, The Future of Internet and How to Stop It, New Haven - London 2008. 
Dotyczy to m.in. smartfonów czyniącymi nas terminalami Sieci, z której wszystko może przez nas „przepłynąć”. Interakcje między człowiekiem a osobistym komunikatorem/smartfonem są dzisiaj motorem zmian we wszystkich dziedzinach. Należy zaznaczyć, że im bardziej komórka czy jakikolwiek inny gadżet jest smart, tym większa satysfakcja z jego użytkowania, ale też nikła świadomość tego, że oznacza to większe ryzyko śledzenia użytkownika. Dominują dziś urządzenia mobilne, użytkowane nomadycznie, co oznacza o wiele większą ilość danych niż przy użytkowaniu stacjonarnym.

Chodzi zatem o strategię korzystną dla korporacji sieciowych (corporate-driven), a nie dla użytkowników (user-centered). Za równie istotny, a może nawet istotniejszy, czynnik Zittrain uznaje procesy demograficzne w populacji internautów. Internet przestaje być domeną młodocianych geeków, którzy „chcą się wyszumieć”. Użytkownicy wraz z wiekiem stają się coraz bardziej stateczni, a ponadto do Sieci wchodzą starsze populacje, 50+, które wcześniej nie miały z nią do czynienia. Tej dojrzalszej wiekowo części społeczeństwa sieciowego zależy bardziej na bezpieczeństwie, ochronie przed ryzykiem i stabilnym Internecie, które to cechy młodzi użytkownicy lekceważą, fascynując się możliwościami tego medium.

\section{Dwa trendy}

Dalsze omawianie dyskursów o wolności i zniewoleniu w Internecie nie wydaje mi się szczególnie płodne, każdy sąd może być uprawniony w zależności od sytuacji. Za bardziej interesujące i celowe uznaję przedstawienie dwóch realnych trendów, które wiele mówią o relacji między wolnością, a tym, co skłonni jesteśmy uznać za zniewolenie w Sieci. Słowem, za każdym z rozlicznych stanowisk stoją mocne argumenty, ale często rodzi się pokusa generalizacji jakiegoś trendu, co naraża badacza na popełnienie błędu pars pro toto. To sprawia, że z powodu rozlicznych trendów, jakie znamionują społeczeństwo XXI wieku nie da się go okreslić jednym przymiotnikiem, choć często się tak czyni.

W niniejszym artykule skoncentruję się na ich analizie bez rozstrzygania, na ile są one sprzeczne, na ile komplementarne, nawzajem się wzmacniające, na ile zaś plasują się w różnych porządkach i nie można ich analizować w jednej skali. W moim przekonaniu pochylenie się nad tym problemem jest istotne, jeśli chce się uchwycić kształty społeczeństwa, jakie rodzi się na ich przecięciu. To pozwoli uchwycić nowe wymiary społeczeństwa, z którymi socjologia musi się zmierzyć. 
Pierwszy trend to społeczeństwo rozproszone, spersonalizowane, hiperindywidualistyczne, drugi to społeczeństwo zmierzające do biurokratyzacji, proceduralizacji, certyfikacji, kwantyfikacji, monitoringu i nadzoru. Między tymi trendami zachodzi zarówno relacja wymiany, jak i konfliktu. Z jednej strony nawzajem się one napędzają, jako pozytywne sprzężenie zwrotne, z drugiej - wzajemnie polaryzują.

Im więcej społeczeństwo „produkuje” różnorodności - zdarzeń, procesów, zjawisk, im więcej społecznego tworzenia rzeczywistości - a jest go coraz więcej dzięki potęgowemu rozkładowi interakcji i relacji w sieciach społecznych, powodowanemu przez nowe wydajne technologie komunikacyjne - tym większa jest pokusa monitorowania tych zdarzeń i procesów w imię governance, przewidywalności, skutecznego zarządzania różnorodnością, które staje się cenioną kompetencją. Im więcej zaś biurokratyzacji, proceduralizacji, monitoringu i nadzoru, tym większa potrzeba wyłamywania się z procedur, prywatyzacji norm, personalizacji, różnicowania. Skłania to do postawienia tezy, że w obecnym systemie społecznym mamy do czynienia z przyrostem widzialnej wolności, autonomii jednostki, mobilności, a jednocześnie z przyrostem niewidzialnej kontroli, śledzenia ruchów i zachowań; słowem, jedno napędza drugie, co prowadzi do wzrostu złożoności, zjawisk emergentnych i procesów kumulacyjnych. Różnica w porównaniu z poprzednią epoką - społeczeństwem przemysłowym polega na tym, że o sposobie, w jaki członkowie społeczeństwa korzystają z wolności, po prostu wie się więcej dzięki technologiom pozwalającym rejestrować dane, przekształcać je w informację i integrować z posiadaną wiedzą o społeczeństwie. Ta zmiana ma ogromne znaczenie dla wszystkich sfer życia: demokracji, gospodarki, kultury.

Dążenie do monitorowania, pozyskiwania danych i informacji o obywatelach obecne było zawsze w systemach nie tylko niedemokratycznych, był to bowiem element władzy czy - jak twierdzą Michel Foucalt ${ }^{24}$ i George Gilder $^{25}$ - „wiedzo-władzy”. Podobnie w kręgu cywilizacji zachodniej istniała tendencja do uniezależniania się jednostek i grup od wszelkiej władzy.

Widać więc z jednej strony trend ku biurokratyzacji i nadzorowi nad społeczeństwem, z drugiej zaś - ku różnicowaniu się, rozpraszaniu, personalizowaniu, segmentacji i fragmentacji. Pierwsze cechuje się strukturą sieciową (kłączową), drugie zaś - hierarchiczną, linearną. Są one zarazem

${ }^{24}$ M. Foucault, Nadzorować i karać. Narodziny więzienia, tłum. T. Komendant, Warszawa 1993.

${ }^{25}$ G. Gilder, Knowledge and Power. The Information Theory of Capitalism and How It Is Revolutionizing Our World, Washington 2013. 
symbiotyczne i anabiotyczne i nie mogą istnieć bez siebie. Można je wyodrębniać jedynie dla celów analitycznych, w społecznej praxis się one bowiem przeplatają. Nie można też a priori zakładać, że jeden jest z definicji zły, a drugi dobry, oba mają dobre, ale też Janusowe oblicze.

Użyta zatem w artykule trawestacja tytułu dzieła Michela Foucaulta oznacza, że „nadzorować” to rejestrować, przetwarzać i „nie karać”, to utrzymać wolność działania w sieciach, aby zapewnić systemowi innowacyjność i zwiększyć jego produktywność. Do tego jednak przede wszystkim potrzebna jest wolność.

Niektórzy badacze wskazują na silną opozycję: centralizacja - decentralizacja społeczeństwa. Okazuje się jednak, że nie musi tak być, monitoring nie implikuje bowiem centralizacji, możliwa jest zdecentralizowana kontrola, a często bywa tak, że mamy do czynienia nie tyle z Wielkim Bratem, ile z „braćmi mniejszymi”. Media cyfrowe są pierwszą generacją mediów, które „decentralizują nadzór” - każdy może wchodzić w życie jednostki, śledząc jej relacje społeczne, naruszając prywatność (w każdej chwili narażeni jesteśmy na fotografowanie czy rejestrowanie głosu). Nadzór obecny jest w nas samych, co ujawnia się w przemożnej potrzebie podglądania.

Można wskazać następujące przyczyny skłonności do nadzorowanej wolności:

1. Pozyskiwanie danych i przekształcanie ich w informacje jest podstawą społeczeństwa wiedzy, a zarazem wiedzy o nim. Dane i informacje to nowe zasoby, nad którymi kontrola stanowi element władzy. Zapowiada się przełom w nauce o społeczeństwie, który przyniesie wielką zmianę społeczną i kulturową, z implikacjami dla zarządzania, ekonomii, polityki. Amerykański fizyk Marc Buchanann ${ }^{26}$ na podstawie wielu badań w ramach social network analysis twierdzi, że nauki społeczne przestaną być „ubogim krewnym” innych nauk. Brak twardych danych narażał je w przeszłości na spekulacje i często prowadził w ślepy zaułek. Fizyka ma swoje teleskopy, zderzacz hadronów i dobrze wyposażone laboratoria. Biologia dzięki odczytaniu sekwencji genomu stała się po części nauką informatyczną. Wraz z coraz szerszym zakresem computingu w badaniach wszystkie nauki staną się poniekąd naukami informatycznymi. Dotyczy to także humanistyki, która w wersji cyfrowej zyskuje nowe horyzonty ${ }^{27}$.

${ }^{26}$ M. Buchanan, Social Networks. The Great Tipping Point Test, „Social Scientist, Magazine Issue” 26.07.2010.

${ }^{27}$ A. Radomski, R. Bomba, Zwrot cyfrowy w humanistyce. Internet - nowe media kultura 2.0, Lublin 2013. 
2. Im więcej systemów technicznych, tym więcej ryzyka i złożoności, którą nie da się zarządzać. Imperatywem staje się zapanowanie nad szybkością procesów, która wywołuje pozytywne sprzężenia zwrotne, a tylko takie powodują zmiany. Gromadzenie danych ma chronić przed tymi zagrożeniami, choć można tu zauważyć pewną sprzeczność - zapanowanie nad złożonością procesów społecznych świata wymaga tworzenia coraz większej ilości danych, informacji i wiedzy. Złożonością trudno jest zarządzać. Stąd tęsknota za „kryształowym pałacem” w postaci „cyfrowego nieba” czy „chmury danych”, w której wszystko jest policzalne. Kryje się w tym jednak pułapka: coraz więcej danych, coraz większa skala ich przetwarzania i obciążania nimi środowiska informacyjnego, co nakręca nową spiralę złożoności. Zatem im więcej informacji zintegrowanych z posiadaną już wiedzą i ją poszerzających, tym więcej nowych źródeł danych, które „przestają milczeć” i z których czytamy jak z otwartej księgi. To już są technologie samozapisu i samopokazu.

3. Żywa praca ludzka jest coraz częściej zastępowana przez maszyny, które budują drugą gospodarkę. Jesteśmy stale w zasięgu Ubicomp (Ubiquitous computing) - wszędobylskiej informatyki. Pod materialną skorupą komunikują się ze sobą maszyny pełne danych. Ubicomp to stróż nocny w wersji cyfrowej; niewidzialna ręka rynku i władzy. Informatyka coraz częściej zamienia relacje między ludźmi w komunikaty między maszynami; ponad 50\% transakcji giełdowych dokonuje się za pośrednictwem maszyn. Żyjemy w epoce Watsonów. Watson to program komputerowy, który gra (i wygrywa) w Jeopardy, ale może też diagnozować stan zdrowia noworodków.

Binaryzacja języka sprawia, że komputer zintegrowany z urządzeniami operuje jednym kodem i dzięki technologii RFiD informuje o ich pracy i użytkownikach. Maszyny potrzebują coraz więcej materiału informacyjnego, i tak naprawdę są sterowane przez informację jak samochody bez kierowcy. Potrzebne są gigabajty danych, aby uzbroić informacyjnie roboty czy raczej uzbrojone lub nieuzbrojone bezzałogowce, zwane dronami. Z tego względu Stany Zjednoczone gromadzą tak ogromne ilości danych. Dzięki Big Data można bowiem zyskać przewagę konkurencyjną, dlatego na pozyskiwanie danych nastawiony jest wywiad ekonomiczny, aby np. „prześwietlić” prowadzone negocjacje kontraktowe i na bazie tej wiedzy zaproponować własną ofertę. Chodzi także o zdobywanie jak największej liczby danych o konsumentach i ich potrzebach, aby móc im zaoferować innowacyjne produkty.

4. Monitoring całego społeczeństwa, w tym pozyskiwanie, gromadzenie i przetwarzanie danych o nim, wymaga ogromnych mocy technicznych 
i zaangażowania tysięcy ludzi. Bardziej skuteczne, a z pewnością mniej kosztowne, jest pozyskiwane danych o superwzmocnionych jednostkach, które mogą komuś pomóc lub wyrządzić szkodę, np. zaszkodzić wielkiej organizacji, a nawet całym państwom, gdyż dysponują środkami technicznymi, jakie w przeszłości stosowały korporacje czy rządy. Wystarczy komputer podłączony do Sieci i odpowiednie kompetencje, aby pojawiła się ta różnica. Cywilizacja infoglobalna daje wielką siłę netterowi. Takiej jednostki nie można pozostawić bez kontroli, może ona bowiem zaatakować z każdego punktu cyberprzestrzeni. Jest niebezpieczna, nie uznaje państw, hierarchii, tajemnic, własności intelektualnej, które są podstawą ładu światowego czy tego, co jeszcze zeń pozostało.

Nie jest to sytuacja hipotetyczna - takich przypadków było już wiele, by wspomnieć o Edwardzie Snowdenie czy Julianie Assange’u, twórcy Wikileaks. Dlatego też kontrola nad takimi jednostkami i predykcja ich zachowań ma tak wielkie znaczenie, zwłaszcza że zachowania te bywają nieprzewidywalne. Nie działają, albo działają niewystarczająco, normy grupowe, które pozwalały takie zachowania przewidywać. W interesie rządów i biznesu jest to, by nie byli oni Anonymous, lecz by się ujawniali na wszystkich możliwych platformach komunikacyjnych, aby można było śledzić ich praktyki subwersywne w ramach tego, co można dziś nazwać „panoptykonem dla zbuntowanych”.

Pojawia się tu pytanie, czy w monitorowanym ładzie możliwe i potrzebne są jeszcze demokracja i wolność. Margines wolności był największy wtedy, gdy jednostka miała ograniczone możliwości wywołania zmiany typu individual driven change; nie mogła stanowić zagrożenia dla systemu. Istniała asymetria informacji i wiedzy na korzyść rządów i korporacji. Gdy asymetria ta zaczęła się zmniejszać na rzecz jednostki, jej wolność, uzbrojona w potężne narzędzia, zaczęła wywoływać ryzyko. Pod koniec lat 90. David Brin wieszczył nadejście społeczeństwa transparentnego. W książce The Transparent Society ${ }^{28}$ postuluje, by każdy obywatel miał poprzez własny PIN dostęp do rządowych i biznesowych baz danych, żeby mógł wiedzieć, kto i jakie informacje o nim gromadzi. Bez tego mówienie o wolności nie ma sensu. Chodzi o to, aby dysponowanie informacją i wiedzą nie dawało komuś przewagi. Podobnie francuski filozof Jean-François Lyotard postulował, aby rządy otworzyły dla wszystkich swoje bazy danych. To był rewolucyjny pomysł, choć uznany za utopijny, ale praktyka ostatnich dwóch

${ }^{28}$ D. Brin, The Transparent Society: Will Technology Force Us to Choose Between Privacy and Freedom?, New York 1999. 
dekad - eksplozji Internetu - pokazała, że znosił on monopole informacyjne charakterystyczne dla epoki przemysłowej.

5. W sytuacji chaosu postnormatywnego i prywatyzacji moralności różnicują się wzory ekspresji, a nonkonformizm i ekscentryczność stają się nową normą. Słabnie kontrola ze strony społeczności lokalnej, kontrolna funkcja tradycyjnych instytucji odpowiedzialnych za pierwotną (rodzina) i wtórną (szkoła, kościoły) socjalizację, zapewniających porządek społeczny. Wobec kryzysu instytucji jedyną szansą zarządzalności i sterowności staje się monitoring przez technologie. W sytuacji nieskuteczności prawa, zwłaszcza w obszarze ochrony własności intelektualnej, wkracza technologia, która je zastępuje, np. w postaci blokady dostępu do wrażliwych danych i informacji.

6. Dane o ludziach stają się niezbędne, zaś człowiek staje się najważniejszym zasobem jako wytwórca, konsument, „mięso wyborcze i reklamowe” - fundament systemu rynkowego i demokratycznego. Pokusa rejestrowania danych jest tym silniejsza, że użytkownicy Sieci sami chętnie je ujawniają, nawet te najbardziej prywatne, intymne. Nie czują potrzeby opuszczania zasłon w swoich cyberoknach.

7. Podłączone do sieci komputery i ich rosnące możliwości procesoryczne, pamięciowe i kalkulacyjne zachęcają do budowania Big Data, rejestrowania ludzkiego doświadczenia w systemach, tym bardziej gdy te zasoby danych ma się w swoich serwerowniach. O tym, jakie znaczenie mają bazy danych, świadczy to, że serwerownie, centra analizy danych stanowią dziś najbardziej strzeżone obiekty. W potocznym znaczeniu owe bazy to magazyny liczb, danych osobowych oraz różnych innych wielkości i wartości. Bazą danych jest każdy zdigitalizowany tekst kultury (czyli także mapy, obrazy itd.) w najszerszym rozumieniu semiotycznym, a więc zarówno ten Gutenbergowski, jak i Zuckerbergowski. Chodzi o tekst, który pozwala na nielinearne, „kłączowe” wyszukiwanie, indeksowanie, (geo)tagowanie, wizualizację i fonizację, taktylność i inne zabiegi nie do pomyślenia przy tekście analogowym. W tym znaczeniu bazą danych będą np. dzieła Szekspira zapisane w kodzie binarnym.

Komputer znacznie usprawnia procedury: uczelnia, szkoła, fabryka, więzienie, hipermarket to zasoby ludzkie, którymi zarządzanie wymaga coraz większej proceduralizacji. Im bardziej wszystko jest connected, a nawet overconnected ${ }^{29}$, tym łatwiejszy, a tym samym nieuchronny staje się monitoring, gdyż coraz więcej relacji międzyludzkich oraz tych między

${ }^{29}$ W.H. Davidow, Overconnected: The Promise and Threat of the Internet, New York 2011. 
człowiekiem a maszyną jest zapośredniczonych i coraz więcej aktywności przenosi się do przestrzeni cyfrowej.

8. Wiek ma istotny wpływ na postrzeganie prywatności - młodsi użytkownicy Sieci inaczej niż starsze pokolenie rozumieją takie pojęcia, jak: wolność, kontrola czy prywatność, tak jak my inaczej je rozumiemy niż ludzie z epoki feudalnej. Zachętą do poszerzania Big Data jest zgoda większości na to, że monitoring redukuje zagrożenia dla bezpieczeństwa; życie nawet w monitorowanym komforcie jest bardziej atrakcyjne niż bez niego. Analizy frekwencyjne dyskursów medialnych i politycznych pokazują, że po atakach terrorystycznych 9 września 2001 r. „bezpieczeństwo” wysunęło się na czoło, wyprzedzając takie pojęcia, jak: „wolność”, „globalizacja” czy „Internet”. Bezpieczeństwo jawi się więc jako nowa narracja postępu. Na innowacyjne projekty technologiczne, które mają zapewnić bezpieczeństwo systemów, przeznacza się coraz więcej środków, które wcześniej kierowano na szybkość i wydajność.

9. Codzienne wydarzenia społeczne, nowe formy aktywności, tweetowanie, kultura popularna tworzą nowe zasoby, które można eksploatować. W Sieci mieszają się role nadawcy i odbiorcy, każdy może być dziś jednym i drugim, co określa się mianem sendceivingu (sending \& receiving). Wyrazem nowych form życia codziennego są zmiany w sferze języka potocznego: chatowanie, sms- i mms-owanie, blogowanie, tweetowanie, surfowanie, fejsbukowanie, lajkowanie, cyberrandkowanie. Wszystkie te formy aktywności są łatwo rejestrowalne. To sygnały zmian w życiu codziennym, dowód na to, że coraz większego znaczenia nabiera samozaopatrzenie ludyczne i poznawcze, redukujące dominującą wcześniej rolę producentów kultury popularnej.

Zbiorowość ludzka staje się „,społeczną fabryką”, gdzie ma miejsce praca wielości ${ }^{30}$, z której już się czerpie, a będzie się czerpać jeszcze więcej, bo są to zasoby kultury, w której rodzą się nowe trendy, mody, upodobania i strumienie symboli, przetwarzanych przez media i przemysły kultury, banki, firmy telekomunikacyjne itp. ${ }^{31}$ Chodzi o zdarzenia i działania przejawiające się w codziennych doświadczeniach ludzi: miłości, macierzyństwie, traktowaniu swojego ciała, podróżach, zakupach, zabawie, humorze, kulinariach, emocjach, religii, mitach, opowieściach, podaniach, legendach, lokalnej wiedzy o leczeniu, budownictwie, pielęgnacji, zwyczajach językowych

${ }^{30}$ M. Hardt, A. Negri, Multitude...

${ }^{31}$ K. Krzysztofek, Paratekst jako postfabrykat kultury, w: A. Gwóźdź (red.), Pogranicza wizualności, Kraków 2010, ss. 94-112. 
i gwarach, stylach życia, sztuce ludowej, tańcu, relacjach międzyludzkich, sposobach ekspresji, przekleństwach, znaczeniach, historii itd.

Zasilanie tych złóż to swego rodzaju wolontariat dla prywatnych korporacji, który określa się jako crowdsourcing. Produkty wytworzone w kooperacji z klientami/konsumentami i z wykorzystaniem ich opinii czy sugestii lepiej się sprzedają. Wiele produktów, zwłaszcza w sferze nowych technologii, można modyfikować, co daje firmom szansę tworzenia nowych linii produktów dzięki pracy konsumentów/prosumentów. Użytkownik zaś zyskuje możliwość spersonalizowania produktu według własnych potrzeb.

Temu też służy analityka kultury, m.in. YouTube, który pozwala wyławiać zdolnych twórców z tłumu zamieszczających tam swoje materiały, a jednocześnie badać zainteresowania użytkowników tego serwisu. Wiedza na ten temat daje kanałom telewizyjnym orientację w tym, co ludzi interesuje i czym te kanały zapełniać. Jest to sposób na wychwytywanie trendów w kulturze, zwiększanie ich postrzegalności.

\section{Konkluzje}

W tym świetle istotne wydaje się pytanie, czy kultura wytworzy jakieś przeciwciała, żeby odbudować zdrową tkankę, jak to już nieraz bywało w historii cywilizacji ostatnich stuleci, zdominowanej przez technikę. Brakuje bowiem teorii krytycznej na miarę Szkoły Frankfurckiej, której głos byłby dziś równie mocny jak ten sprzed kilku dekad. Pewne nadzieje daje rozwój studiów nad nadzorem, które być może będą w stanie uwrażliwić społeczeństwa na zagrożenia. Jaskółką takich działań jest „Wezwanie do obrony demokracji w erze cyfrowej”32, podpisane przez kilkuset pisarzy i wydawców z 83 krajów, wśród nich noblistów. Przesłanie apelu jest jednoznaczne: jesteśmy świadkami zmasowanej inwigilacji, która niszczy ideały wolności i demokracji. Człowiek inwigilowany przestaje być wolny, a inwigilowane społeczeństwa przestają być demokratyczne. Inwigilacja to kradzież naszych danych, które nie są własnością publiczną. To ostatnie stwierdzenie jest istotne, wynikają bowiem zeń istotne konsekwencje. Jeśli inwigilacja jest kradzieżą, to usprawiedliwia tym samym kradzież zawartości, którą chce się chronić reżimem ochrony własności intelektualnej. Jeśli jednym wolno kraść, to wolno też innym. W ten sposób powstaje na naszych oczach świat, w którym wszyscy kradną. A jeśli wszyscy kradną, to w istocie nie kradnie nikt, bo w postnormatywnym chaosie uczciwość nie jest już normą.

32 „Gazeta Wyborcza” 10.12.2013. 
W 1983 r. mój opiekun naukowy w Massachusetts Institute of Technology, nieżyjący już profesor Ithiel de Sola Pool, w czasach gdy Internet dopiero raczkował, głosił nadejście technologii wolności ${ }^{33}$, którymi miały stać się technologie informacyjne. Równo 30 lat później inny Amerykanin, filozof, historyk i programista, Eben Moglen ${ }^{34}$ ogłosił narodziny machina universalis, która wszystko o nas wie, podpowiada, jak mamy żyć i przewiduje nasze dobre i złe uczynki. Kto ma rację, czy też kto ma więcej racji, tego jeszcze nie wiemy, ale dynamika procesów zachodzących w świecie cyfrowym i na jego przecięciu z analogowym wskazuje, że Moglen jest bliższy prawdy, choć sam nie kapituluje, wierząc, że człowiek i jego kultura w jakiś sposób uchronią się przed ziszczeniem się Benthamowskiej wizji panoptykonu.

Zdanie się na inteligentne systemy analityczne i raporty, jakie one wytwarzają, niesie spore ryzyko. Należałoby zbadać, czy zaawansowana analityka nie grozi algorytmizowaniem ludzi, czy nie zdają się oni na mądrość systemu; czy nie prowadzi do podświadomego niedoceniania własnej interpretacji i ewaluacji danych, bo „maszyna wie lepiej”. Na takim psychologicznym gruncie może rodzić się bezkrytyczna postawa wobec systemów informacyjnych. Wybitni intelektualiści Stanisław Lem i Paul Virilio przestrzegali, że produkcja danych grozi tym, iż staną się one raczej śmietnikiem, wysypiskiem cyfrowym niż sezamem. Lem straszył „bombą megabitową”35, a Virilio „bombą informacyjną”36. Ten drugi przywołuje Einsteina, który był przekonany, że wybuch tej bomby jest tylko kwestią czasu, w wyniku czego rozpęta się wojna informacyjna, oparta na globalnej interaktywności, a informacja zleje się z dezinformacją.

W ciągu niespełna kilku lat wraz z wynalazkiem Big Data zmieniła się perspektywa: to już nie bomba, a nadzwyczajna szansa czerpania z nowego bogactwa.

\section{Literatura}

Anderson Ch., The Long Tail, New York 2006.

Battelle J., Szukaj. Jak Google i konkurencja wywołali biznesowq i kulturowq rewolucję, Warszawa 2006.

Benkler Y., The Wealth of Networks: How Social Production Transforms Markets and Freedom, Yale 2006.

Breton Ph., Le culte de l'internet: une menace pour le lien social?, Paris 2000.

33 I. de Sola Pool, Technologies of Freedom, Cambridge, Mass. 1984.

${ }^{34}$ E. Moglen, Wolność w chmurze i inne eseje, Warszawa 2013.

35 S. Lem, Bomba megabitowa, Kraków 1999.

${ }^{36}$ P. Virilio, Bomba informacyjna, Warszawa 2006. 
Brin D., The Transparent Society: Will Technology Force Us To Choose Between Privacy And Freedom?, New York 1999.

Buchanan M., Social Networks. The Great Tipping Point Test, „Social Scientist” 26.07.2010.

Carr N., The Shallows. What the Internet is Doing to Our Brains, New York 2010.

Davidow W.H., Overconnected: The Promise and Threat of the Internet, New York 2011.

Foucault M., Nadzorować i karać. Narodziny więzienia, tłum. T. Komendant, Warszawa 1993.

Gilder G., Knowledge and Power. The Information Theory of Capitalism and How It Is Revolutionizing Our World, Washington 2013.

Hardt M., Negri A., Multitude. The War and Democracy in the Age of Empire, New York 2004.

Hofmokl J., Internet jako dobro wspólne, Warszawa 2008.

Jenkins H., Kultura konwergencji, tłum. M. Bernatowicz, M. Filipiak, Warszawa 2006.

Keen A., Kult amatora. Jak Internet zabija kulturę, tłum. M. Bernatowicz, K. Topolska-Ghariani, Warszawa 2007.

Kerckhove D. de, Inteligencja otwarta. Narodziny społeczeństwa sieciowego, tłum. A. Hildebrandt, Warszawa 2001.

Krzysztofek K., Open Knowledge Society in the Epoch of Networks, w: B. Poskrobko (red.), Sustainable Development versus Knowledge-Based Society, Białystok 2009.

Krzysztofek K., Paratekst jako postfabrykat kultury, w: A. Gwóźdź (red.), Pogranicza wizualności, Kraków 2010.

Lanier J., Digital Maoism: The Hazards of the New Online Collectivism, http://www.sampletheweb.com/2006/06/09/digital-maoism-the-hazards-of-the-new-online-collectivismby-jaron-lanier/ [12.08.2014].

Lem S., Bomba megabitowa, Kraków 1999.

Lessig L., Wolna kultura, Warszawa 2005.

Levy P., Collective Intelligence. Mankind's Emerging World in Cyberspace, Reading, Mass. 1997.

Moglen E., Wolność w chmurze i inne eseje, Warszawa 2013.

Morozov E., To Save Everything, Click Here: The Folly of Technological Solutionism, New York 2013.

Radomski A., Bomba R., Zwrot cyfrowy w humanistyce. Internet - nowe media - kultura 2.0, Lublin 2013.

Raymond E.S., The Catheral and the Baazar. Musing on Linux and Open Source by an Accidental Revolutionary, New York 2001.

Rheingold H., Smart Mobs. The Next Social Revolution. Transforming Cultures and Communities in the Age of Instant Access, Cambridge, Mass. 2002.

Rheingold H., Savery A., Vian K., Technologies of Cooperation, Palo Alto 2005.

Sola Pool I. de, Technologies of Freedom, Cambridge, Mass. 1984.

Stoll C., Krzemowe remedium, Poznań 1996.

Surowiecki J., The Wisdom of Crowds: Why the Many Are Smarter Than the Few and How Collective Wisdom Shapes Business, Economies, Societies and Nations, New York 2005.

Tapscott D., Williams A.D., Wikinomics, How Mass Collaboration changes Everything, Richmond 2006.

Thompson C., Smarter Than You Think. How Technology Is Changing Our Minds For the Better, New York 2012.

Virilio P., Bomba informacyjna, Warszawa 2006.

Zittrain J.L., The Future of Internet and How to Stop It, New Haven - London 2008. 